\title{
RBEP
}

\section{Ensino de Filosofia e cidadania: uma abordagem a partir de Gramsci*}

Renê José Trentin Silveira

\section{Resumo}

Pretende discutir a relação entre ensino de Filosofia e preparo para a cidadania. Inicialmente, procura-se identificar e problematizar a concepção oficial dessa relação por meio do exame da Constituição Federal, da Lei de Diretrizes e Bases da Educação Nacional (LDB) e dos Parâmetros Curriculares Nacionais (PCN) para o Ensino Médio. Verifica-se nesses documentos a presença de uma concepção liberal de cidadania, entendida como exercício consciente de direitos e deveres e como preparo para o ingresso no mercado de trabalho, em nome da qual se justifica, do ponto de vista oficial, a inclusão obrigatória da Filosofia no currículo. Num segundo momento, busca-se contrapor a esta noção de cidadania uma outra, fundamentada em Antonio Gramsci, para quem uma escola

* Este texto serviu de base para a conferência "Filosofia e formação cidadã", proferida pelo autor no Seminário de Filosofia - Filosofia: Formação e Transformação, promovido pelo Instituto de Ciências Humanas e Letras da Universidade Federal do Amazonas, em Manaus, de 12 a 16 de setembro de 2011. verdadeiramente democrática deve ser capaz de transformar todo cidadão em governante. Finalmente, discutem-se algumas implicações dessa noção gramsciana da cidadania para a prática do ensino da Filosofia.

Palavras-chave: Antonio Gramsci; filosofia; filosofia e educação; cidadania; cidadania e educação; ensino médio. 


\section{Abstract \\ Teaching philosophy and citizenship: an approach from Gramsci}

The present article intends to discuss the relation between teaching Philosophy and preparation for citizenship. Firstly, it is intended to identify and problematize the official notion of this relation by examining the Federal Constitution, the National Education Basis and Guidelines Law $(L D B)$ and the National Curricular Parameters for Secondary Education (PCN). A liberal conception of citizenship is seen in these documents, understood as a conscientious exercise of duties and rights and as preparation for the labour market, which justifies, in an official point of view, the mandatory presence of Philosophy in the curriculum. Secondly, it is seek to counteract this notion of citizenship one another, founded based on Antonio Gramsci, for whom a truly democratic school must be able to transform every citizen into ruler. Finally, we will discuss some applications of this gramscian notion of citizenship in the teaching of Philosophy.

Keywords: Antonio Gramsci; philosophy; philosophy and education; citizenship; citizenship and education; secondary education.

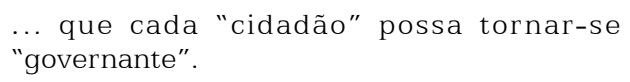

(Gramsci, 2006, C 12, § 2, p. 50)

A principal justificativa que se encontra na legislação educacional para a inclusão obrigatória da Filosofia no currículo do ensino médio é a importância a ela atribuída no preparo dos jovens para o exercício da cidadania. Mas o que isso significa objetivamente? Qual é, de fato, a expectativa do Estado em relação à disciplina no que se refere a esse preparo? Que noção de cidadania alimenta essa expectativa? Trata-se da mesma cidadania que têm em mente os educadores e estudantes de Filosofia quando, valendo-se do mesmo argumento, defendem a necessidade do contato dos jovens com o saber filosófico?

Para tentar responder a essas indagações, procurarei, inicialmente, caracterizar a perspectiva oficial da relação entre Filosofia e cidadania, mediante uma breve análise desse conceito na Constituição Federal, na Lei de Diretrizes e Bases da Educação Nacional (LDB) e nos Parâmetros Curriculares Nacionais (PCN) para o Ensino Médio. Em seguida, apresentarei, ainda em esboço, outra concepção da cidadania, oposta à anterior e que, a meu ver, encontra sustentação nas teses de Antonio 
Gramsci. Finalmente, discutirei algumas possíveis implicações da concepção gramsciana da cidadania para a prática do ensino da Filosofia.

Compreender e problematizar a relação entre ensino de Filosofia e cidadania é essencial para que se "tenha os pés no chão" quanto ao potencial do trabalho pedagógico com essa disciplina, evitando-se tanto a visão ufanista e idealista, que lhe atribui superpoderes, confiandolhe a missão quase mágica de redimir os jovens de sua consciência supostamente ingênua e alienada, quanto a postura derrotista e imobilista que tende a vê-la como mais um ingrediente a se diluir na sopa rala e insossa de conteúdos em que se teria transformado o currículo escolar, incapaz, portanto, de dar sustância e vigor à formação intelectual e cultural dos jovens. Espero que o presente artigo contribua de algum modo para a superação desses dois extremos.

\section{Filosofia e cidadania na perspectiva oficial}

\section{A Constituição Federal}

A Constituição de 1988, por sinal, também chamada de "Constituição cidadã", em seu art. $1^{\circ}$, define o Brasil como um Estado Democrático de Direito que tem na "cidadania" um de seus fundamentos (inciso II). A lei não enuncia explicitamente o que vem a ser essa cidadania, porém, depreende-se de sua leitura que o termo é utilizado em dois sentidos: como sinônimo de nacionalidade e como condição que possibilita o exercício de direitos e deveres.

No primeiro sentido, a cidadania é reconhecida a partir de dois princípios básicos: o jus soli (do latim: direito de solo) e o jus sanguinis (direito de sangue). Pelo jus soli, a cidadania ou nacionalidade é atribuída a uma pessoa de acordo com o local de seu nascimento. Diz-se, por exemplo: "Todas as pessoas nascidas no Brasil têm cidadania brasileira". Por sua vez, pelo jus sanguinis, o critério de cidadania é dado pela ascendência da pessoa, isto é, pela nacionalidade de seus pais. Nesse sentido, diz-se: "Fulano nasceu e vive no exterior, mas, como é filho de brasileiros, adquiriu cidadania brasileira". ${ }^{1}$

O segundo sentido, que é o que nos interessa aqui, está diretamente ligado ao primeiro. Uma vez reconhecida a cidadania no sentido do pertencimento a um determinado país, a um Estado, o cidadão se torna beneficiário de certos direitos e submetido a certos deveres fixados e garantidos por esse mesmo Estado. No caso do Brasil, a Constituição estabelece como direitos e deveres de todo cidadão: a vida, a liberdade, a igualdade, a segurança, a propriedade (art. $5^{\circ}$ ), a educação, a saúde, a alimentação, o trabalho, a moradia, o lazer, a segurança, a previdência social, a proteção à maternidade e à infância, a assistência aos desamparados (art. $6^{\circ}$.), a soberania popular, o sufrágio universal, o voto

1 Na Constituição Federal, a cidadania entendida como nacionalidade é tratada no art. 12. direto e secreto (art. 14), entre outros. É esse o significado que se atribui ao termo cidadania quando se diz, por exemplo, "Votar é uma questão 
de cidadania" (é exercer um direito e um dever de cidadão), ou quando o próprio texto constitucional determina, em seu art. 205, que "a educação deve preparar os jovens para o exercício da cidadania" (prepará-los para que conheçam seus direitos e deveres, exijam o respeito aos primeiros e cumpram com responsabilidade os segundos). A Carta Magna, porém, não esclarece de que forma a educação deve cumprir essa missão, tarefa que será reservada à legislação específica.

\section{$A L D B$}

Na LDB (Lei n 9.394, de 20 de dezembro de 1996), a vinculação entre educação e cidadania aparece logo no art. $2^{\circ}$, dedicado a enunciar os princípios e fins da educação nacional. De acordo com esse artigo, a educação nacional cumpre uma tríplice finalidade: "o pleno desenvolvimento do educando, seu preparo para o exercício da cidadania e sua qualificação para o trabalho" (Brasil, 1996 - grifos meus). Note-se que a preparação para a cidadania aparece acompanhada da qualificação para o trabalho. Essas mesmas finalidades reaparecem em termos ligeiramente diversos no art. 22, referente à educação básica (ensino fundamental e médio): "desenvolver o educando, assegurar-lhe a formação comum indispensável para o exercício da cidadania e fornecer-lhe meios para progredir no trabalho e em estudos posteriores" (grifos meus).

Há, portanto, o reconhecimento da necessidade de uma determinada formação comum, isto é, igual para todos, de responsabilidade da educação básica, sem a qual o exercício da cidadania seria impossível. Que formação seria essa? Que conteúdos e habilidades ela englobaria?

A resposta começa a aparecer no art. 26, o qual estabelece que os currículos da educação básica tenham uma "base nacional comum", que deverá ser complementada, em cada sistema de ensino e nas escolas, por uma "parte diversificada" que atenda às "características regionais e locais da sociedade, da cultura, da economia e da clientela". Quanto aos conteúdos, esses currículos devem abranger, obrigatoriamente: "o estudo da língua portuguesa e da matemática"; "o conhecimento do mundo físico"; e o conhecimento "da realidade social e política, especialmente do Brasil" (art. 26, § $1^{\circ}$ ). Acrescentem-se ainda como componentes curriculares: a "arte" (art. 26, § 2); a "educação física" (art. 26, § 3); a "História do Brasil" (art. 26, § 4); "uma língua estrangeira moderna" (art. 26, § 5); e a "música" (art. 26, § 6). Tem-se, assim, uma primeira indicação dos conteúdos mínimos e obrigatórios considerados indispensáveis para uma formação comprometida com o preparo para a cidadania.

Os conteúdos e habilidades que compõem a formação para a cidadania continuam a ser apresentados nos artigos que tratam especificamente de cada etapa da educação básica. ${ }^{2}$

O ensino médio, que nos interessa mais de perto no momento, deve cumprir quatro finalidades principais, dentre as quais se destaca a da "preparação básica para o trabalho e a cidadania" (art. 35, inciso II - grifos
${ }^{2}$ É interessante notar que, de todos os níveis que compõem a educação básica regular, a educação infantil (arts. 29, 30 e 31) é o único em que não aparecem os termos "cidadania" ou "cidadão" associados aos seus objetivos. Isso parece relevante na medida em que traz à tona a questão da cidadania da criança e de como a lei a concebe e trata. O tema, porém, merece estudo mais aprofundado. Algo parecido ocorre com a educação de jovens e adultos (art. 37). 
3 O adjetivo "necessário" indica algo que é "absolutamente preciso"; "que tem que ser", que é "essencial", "indispensável". Em Lógica, por exemplo, diz-se, no silogismo, que a conclusão é sempre necessária, pois não pode deixar de se seguir às premissas (Cf.: Dicionário Houaiss, versão online. Disponível em: <http:// houaiss.uol.com.br/busca.jhtm? verbete $=$ necess $\% \mathrm{E} 1$ rio\& $\mathrm{x}=0 \& \mathrm{y}$ $=0 \&$ stype $=\mathrm{k}>$. Acesso em: 11 out. 2011).

${ }^{4}$ Dados os limites deste artigo, não será possível analisar aqu as Orientações. Contudo, uma interessante abordagem desse documento pode ser encontrada em Almeida (2011). meus) - novamente cidadania e trabalho aparecem associados. Quanto aos conteúdos e habilidades exigidos para esta preparação, incluem: "educação tecnológica básica"; "compreensão do significado da ciência, das letras e das artes", bem como do "processo histórico de transformação da sociedade e da cultura"; o domínio da "língua portuguesa como instrumento de comunicação, acesso ao conhecimento e exercício da cidadania" (art. 36, inciso I); domínio de duas línguas estrangeiras, sendo uma obrigatória, à escolha da comunidade escolar, e outra optativa, em conformidade com a disponibilidade da escola (inciso III); e, finalmente, "a Filosofia e a Sociologia como disciplinas obrigatórias em todas as séries do ensino médio" (inciso IV).

Com efeito, a obrigatoriedade da Filosofia e da Sociologia foi determinada pela Lei $n^{\circ} 11.684 / 2008$ (Brasil, 2008), que alterou o art. 36 da LDB. Antes dessa lei, essas disciplinas apareciam no parágrafo $1^{\circ}$, inciso III, do referido artigo, com a seguinte redação:

$\S 1^{\circ}$ Os conteúdos, as metodologias e as formas de avaliação serão organizados de tal forma que ao final do ensino médio o educando demonstre:

$[\ldots]$

III - domínio dos conhecimentos de Filosofia e de Sociologia necessários ao exercício da cidadania (grifo meu).

Observa-se nessa antiga redação um dado interessante: ao afirmar a necessidade do domínio de conteúdos de Filosofia e Sociologia para o exercício da cidadania, a lei reconhecia que, sem tais conteúdos, esse exercício seria inviável, impossível. ${ }^{3}$ Aí estaria a justificativa para a obrigatoriedade dessas disciplinas: assegurar um dos objetivos fundamentais da educação básica, que é justamente a formação para a cidadania.

Filosofia e Sociologia, portanto, são as únicas disciplinas do currículo da educação básica cuja necessidade para o exercício da cidadania é explicitamente reconhecida pela lei. A LDB, porém, não especifica de que maneira essas disciplinas contribuem para esse exercício - esta tarefa ficará a cargo dos Parâmetros Curriculares Nacionais e das Orientações Curriculares para o Ensino Médio. ${ }^{4}$ No entanto, a LDB faz uma indicação importante para a reflexão sobre a identidade dessas disciplinas no ensino médio e que fica mais evidente na primeira redação do art. 36: há conhecimentos específicos de Filosofia e Sociologia que precisam ser dominados pelos jovens para que se tornem efetivamente cidadãos. Na perspectiva do legislador, é justamente pela especificidade desses conhecimentos que a presença obrigatória dessas disciplinas no currículo se justifica. Há, portanto, que preservar essa identidade no trabalho pedagógico com essas disciplinas, sob pena de se anular essa justificativa.

Em suma, todos os componentes curriculares da educação básica devem ter como uma de suas diretrizes "a difusão de valores fundamentais ao interesse social, aos direitos e deveres dos cidadãos, de respeito ao bem comum e à ordem democrática" (art. 27, inciso I - grifos meus). No 
que tange à cidadania, portanto, uma das tarefas da educação básica é difundir os valores nos quais ela se fundamenta.

Ora, se isso se aplica a todos os componentes curriculares, vale também para a Filosofia. Poder-se-ia, porém, indagar: A difusão pura e simples de valores associados a uma determinada concepção da cidadania é tarefa compatível com a natureza crítica e reflexiva da Filosofia? Não seria legítimo esperar dela uma atitude mais questionadora, problematizadora, que levasse os estudantes a questionamentos tais como: de que valores se trata, afinal? Como e em que contexto histórico, político e cultural foram estabelecidos? Como são interpretados pela lei? São mesmo legítimos? O que significam "interesse social" e "bem comum" numa sociedade de classes? A ordem social vigente é de fato democrática? Não há, porém, ao menos explicitamente, referências na LDB que sugiram tal papel à Filosofia.

\section{Os PCN - Ensino Médio}

Na perspectiva dos PCN, o ensino médio deve se adaptar às mudanças provocadas na economia (nos processos produtivos e nas relações sociais) pela chamada "terceira revolução técnico-industrial", marcada pelos avanços da microeletrônica e, sobretudo, da informática. Em função desses avanços, o volume dos conhecimentos e das informações produzidas e o ritmo dessa produção são cada vez maiores, o que impõe "novos parâmetros para a formação dos cidadãos" (Brasil, 1999, p. 15). Não se trata mais de acumular conhecimentos, os quais, em pouco tempo, se tornam obsoletos e inúteis. Nessas novas condições, "a formação do aluno deve ter como alvo principal a aquisição de conhecimentos básicos, a preparação científica e a capacidade de utilizar as diferentes tecnologias relativas às áreas de atuação" (Brasil, 1999, p. 15 - grifos meus). O fim último dessa formação é, portanto, capacitar os jovens para atenderem com eficiência às atuais exigências do mercado de trabalho, no qual se encontram incorporados, cada vez mais, os avanços tecnológicos. Estes seriam, fundamentalmente e de fato, os "novos parâmetros para a formação dos cidadãos".

Além disso, a globalização e a abertura dos mercados passaram a exigir um nível mais elevado de "precisão produtiva" e de padrões de qualidade dos produtos, o que impacta também no nível de qualificação exigido aos trabalhadores. Em razão disso, o currículo do ensino médio, segundo os PCN, deve estar comprometido, ao mesmo tempo, com esse "novo significado do trabalho no contexto da globalização" e com o "sujeito ativo, a pessoa humana", que precisa se aprimorar para atuar no mundo do trabalho e na prática social (Brasil, 1999, p. 25). Daí a necessidade de se abandonarem os "modelos tradicionais" de ensino e substituí-los por uma outra concepção da educação: "A perspectiva é de uma aprendizagem permanente, de uma formação continuada, considerando como elemento central dessa formação a construção da cidadania em função dos processos 
sociais que se modificam" (Brasil, 1999, p. 25). Mais adiante, o documento complementa:

Não há o que justifique memorizar conhecimentos que estão sendo superados ou cujo acesso é facilitado pela moderna tecnologia. O que se deseja é que os estudantes desenvolvam competências básicas que lhes permitam desenvolver a capacidade de continuar aprendendo. (Brasil, 1999, p. 25 - grifos meus).

A cidadania supõe, portanto, a capacidade de continuar aprendendo, para que o trabalhador se adapte às constantes mudanças ocorridas no processo produtivo e, assim, siga produzindo de forma eficiente.

Desse modo, em função das transformações observadas no mundo da produção, os PCN, confirmando tendência já presente na LDB e em grande medida inspirados no Relatório da Comissão Internacional sobre Educação para o Século XXI, da Organização das Nações Unidas para a Educação, a Ciência e a Cultura (Unesco), ${ }^{5}$ propõem um "novo paradigma" para o ensino médio, que passa a ser orientado prioritariamente para o desenvolvimento das "competências cognitivas e culturais" (Brasil, 1999, p. 23 - grifos meus) necessárias tanto à inserção dos jovens no mundo do trabalho quanto ao cumprimento de seu papel de cidadãos. Observa-se que nos PCN é ainda mais evidente a vinculação entre exercício da cidadania e qualificação para o trabalho. Na realidade, há nesse documento uma "correspondência entre as competências exigidas para o exercício da cidadania e para as atividades produtivas" (Brasil, 1999, p. 23) que obriga a repensar o papel social da educação. Que competências seriam essas? Trata-se

Da capacidade de abstração, do desenvolvimento do pensamento sistêmico, ao contrário da compreensão parcial e fragmentada dos fenômenos, da criatividade, da curiosidade, da capacidade de pensar múltiplas alternativas para a solução de um problema, ou seja, do desenvolvimento do pensamento divergente, da capacidade de trabalhar em equipe, da disposição para procurar e aceitar críticas, da disposição para o risco, do desenvolvimento do pensamento crítico, do saber comunicar-se, da capacidade de buscar conhecimento. (Brasil, 1999, p. 24).

Percebe-se facilmente que essas competências dizem respeito majoritariamente à esfera da produção e ao perfil de trabalhador que as inovações tecnológicas a ela incorporadas passaram a exigir. É sobretudo para atuar nesse novo contexto produtivo que o ensino médio deve preparar os jovens, e nisso consiste, basicamente, formá-los como

5 O referido documento, também conhecido como Relatório Jacques Delors, foi publicado no Brasil, em 1998, com o título Educação: um tesouro a descobrir. Relatório para a Unesco da Comissão Internacional sobre Educação para o século XXI. Cf.: Delors, 1998. cidadãos.

A cidadania vislumbrada pelos PCN, portanto, requer proporcionar aos jovens condições para que desenvolvam certas competências que lhes permitam adaptar-se às constantes mudanças e inovações por que passam os processos sociais, particularmente o processo produtivo, inserindo-se neles em condições de contribuir para o seu bom funcionamento e seu aprimoramento. Desse modo, a educação estaria favorecendo o 
desenvolvimento social e a eliminação de fatores de exclusão. Trata-se, no fundo, do velho ideal liberal da escola redentora da humanidade, adaptado para o atual estágio de desenvolvimento do capitalismo.

É, pois, a necessidade de adaptação aos processos produtivos que define o modelo de cidadania que deve ser almejado pelo ensino médio. Nenhuma palavra quanto ao desenvolvimento da competência para questionar e, menos ainda, modificar os fundamentos desses processos com vista a adequá-los às necessidades humanas.

\section{Conhecimentos de Filosofia}

Como os PCN veem o papel da Filosofia no ensino médio e em relação à cidadania? Na parte relativa aos Conhecimentos de Filosofia, o documento sugere, logo no início, que as atribuições confiadas pela LDB a essa disciplina e às ciências humanas em geral se devem à necessidade que têm as "sociedades tecnológicas" de indivíduos com uma "educação geral, inclusive em sua dimensão literária e humanista", que os capacite para cooperar conscientemente com essas sociedades (Brasil, 1999, p. 327).

Desse ponto de vista, portanto, a presença da Filosofia no currículo se justifica desde que ela atenda às necessidades das sociedades tecnológicas, isto é, das sociedades que incorporaram os avanços tecnológicos em seus processos sociais e produtivos. A forma como se espera que ela o faça, juntamente com as demais ciências humanas, é proporcionando aos jovens uma formação geral e humanista.

Vê-se assim que, também no que diz respeito aos conhecimentos de Filosofia, a cidadania de que falam os PCN "não dispensa o contexto do trabalho como sentido prático para sua realização" (Brasil, 1999, p. 331).

Desenvolvendo um pouco mais a discussão sobre o papel da Filosofia no ensino médio, os PCN consideram que ela tem uma "contribuição decisiva" a oferecer para a realização das finalidades atribuídas pela LDB a esse nível de ensino, contribuição essa que está relacionada à sua "declarada intenção de buscar o Verdadeiro, o Belo, o Bom" (Brasil, 1999, p. 328). O documento, porém, não esclarece como seria essa contribuição. Na realidade, considera que "não chega a ser necessário insistir, junto aos docentes da disciplina, nas razões que lhe conferem seu enorme e indispensável poder formativo". Contenta-se, assim, em reafirmar a máxima de que "filosofar é preciso!" (Brasil, 1999, p. 328).

No caso da preparação para a cidadania, os PCN entendem que a lei, ao considerar os conhecimentos de Filosofia necessários ao seu exercício, reconhece o "sentido histórico da atividade filosófica" e "enfatiza a competência da Filosofia para promover, sistematicamente, condições indispensáveis para a formação de cidadania plena!" (Brasil, 1999, p. 328). O termo "necessários" é uma clara referência à antiga redação do art. 36 da LDB. Resta saber em que consiste exatamente essa "cidadania plena" e como se espera que a Filosofia contribua para desenvolvê-la nos estudantes. 
Como, afinal, os PCN concebem a cidadania?

Vimos acima que ela não pode dispensar o "contexto do trabalho", pois é este quem lhe proporciona o "sentido prático para sua realização" (Brasil, 1999, p. 331).

Quanto aos valores nos quais ela se fundamenta, são aqueles anunciados pela LDB, já mencionados, a saber, os "fundamentais ao interesse social, aos direitos e deveres dos cidadãos, ao respeito ao bem comum e à ordem democrática", acrescidos dos que "fortaleçam os vínculos de família, os laços de solidariedade humana e de tolerância recíproca" (Brasil, 1999, p. 331):

Tais valores, nucleados a partir do respeito ao bem comum e da consciência social, democrática, solidária e tolerante, permitem identificar mais precisamente a concepção de cidadania que queremos para nós e que desejamos difundir para os outros. (Brasil, 1999, p. 332).

Como se pode facilmente observar, são valores liberais, constitutivos, portanto, de uma concepção também liberal da cidadania, a qual se expressa em três dimensões que se entrecruzam: a estética, a ética e a política.

A dimensão estética é aquela associada à "sensibilidade" e envolve: "capacidade de acesso à própria 'natureza interna'"; "fluência na expressão subjetiva e na livre aceitação da diferença"; "capacidade de 'conhecer-se a si mesmo'"; possibilidade de "elaboração consciente de comportamentos sintomáticos e/ou afetos reprimidos"; "abertura para a diversidade, a novidade e a invenção" (Brasil, 1999, p. 332).

A dimensão ética relaciona-se àquilo que os PCN denominam de "identidade autônoma". Inclui, entre outros, os seguintes aspectos: "consciência e atitude de respeito universal e liberdade na tomada de posição"; "possibilidade de agir com simetria"; capacidade de reconhecer o outro em sua identidade própria"; admitir a "solidariedade como forma privilegiada de convivência humana"; "liberdade para tematizar e, eventualmente, criticar normas"; "agir com reciprocidade com relação àquelas que foram acordadas"; "poder, livremente, decidir sobre o que fazer da própria vida" (Brasil, 1999, p. 332).

A dimensão política, que se expressa na "participação democrática", compreende: "reconhecimento dos direitos humanos"; "igualdade de acesso aos bens naturais e culturais"; "atitude tolerante e protagonismo na luta pela sociedade democrática" (Brasil, 1999, p. 332). Dizem os PCN:

Sem a consciência de direitos e deveres individuais e coletivos, sem a sede de uma justiça que distribua de modo equânime o que foi produzido socialmente, sem a tolerância a respeito de opiniões e estilos de vida "não convencionais" e, sobretudo, sem o engajamento concreto na busca por uma sociedade democrática, não é possível de nenhum modo que se imagine o exercício pleno da cidadania. (Brasil, 1999, p. 332).

Em suma, a "cidadania plena" a que o texto se refere nada mais é do que uma cidadania plenamente liberal, que se atém à afirmação 
formal de direitos e deveres, visando a propiciar o aperfeiçoamento da sociedade democrática - é para essa cidadania que a Filosofia deve contribuir. A forma como ela pode fazê-lo é desenvolvendo nos estudantes as competências que lhes são peculiares, a saber: "Ler textos filosóficos de modo significativo"; "Ler, de modo filosófico, textos de diferentes estruturas e registros"; "Elaborar por escrito o que foi apropriado de modo reflexivo"; "Debater, tomando uma posição, defendendo-a argumentativamente e mudando de posição em face de argumentos mais consistentes"; "Articular conhecimentos filosóficos e diferentes conteúdos e modos discursivos nas Ciências Naturais e Humanas, nas Artes e em outras produções culturais"; "Contextualizar conhecimentos filosóficos, tanto no plano de sua origem específica quanto em outros planos: o pessoal-biográfico; o entorno sociopolítico, histórico e cultural; o horizonte da sociedade científico-tecnológica" (Brasil, 1999, p. 344-349).

Importa registrar que, ao esclarecer o significado dessas competências, os PCN dão indicações interessantes e pertinentes para a prática do ensino da Filosofia. Defendem, por exemplo: "a conexão interna entre conteúdo e método"; a importância de desenvolver nos alunos a "capacidade de problematização" que lhes permita "apropriar-se reflexivamente do conteúdo" estudado; a necessidade de pôr o aluno em contato com a "própria tradição filosófica" e a "história da filosofia", incluindo "conceitos, temas, problemas e métodos" nela elaborados (Brasil, 1999, p. 335); a necessidade de levar em conta a "baixa literatação" dos alunos na escolha da metodologia e do material didático, procurando evitar tanto o academicismo quanto a banalização da Filosofia - entre outras. É a partir dessas diretrizes e visando àquelas competências que a Filosofia pode, segundo os PCN, proporcionar a formação geral e humanista exigida pelas sociedades tecnológicas.

\section{Filosofia, educação e cidadania numa perspectiva gramsciana}

Não há nenhum texto de Gramsci em que essa temática apareça completamente sistematizada e desenvolvida. Discuti-la a partir desse autor, portanto, pressupõe um exercício de interpretação pelo qual se procure articular com coerência seus posicionamentos sobre cada um desses conceitos - é o que me empenharei em fazer a seguir, de modo ainda introdutório, com base nos Cadernos 10, 11 e 12 de sua obra Cadernos do Cárcere.

Talvez a posição mais explícita de Gramsci sobre a relação entre educação e cidadania seja aquela que aparece em uma passagem do parágrafo 2 do Caderno 12, na qual o autor discute o caráter democrático ou não democrático das escolas profissionalizantes e da escola tradicional.

De um modo geral, diz ele, a escola profissional, voltada para a satisfação das necessidades práticas imediatas, costuma ser louvada como democrática e progressista por possibilitar, por exemplo, a qualificação de um operário manual ou a transformação de um agricultor em agrimensor. 
${ }^{6}$ A expressão "formas chinesas" provavelmente se refere à grande distância existente entre intelectuais e povo notada por Gramsci nos países da Ásia Oriental, nos quais ela se manifesta de forma extrema. Ainda no Caderno 12, afirma: "Na China, há o fenômeno da escrita, expressão da completa separação entre os intelectuais e o povo. Na Índia e na China, a enorme distância entre os intelectuais e o povo manifestase, ademais, no campo religioso." (Gramsci, 2006, C 12, § 2, p. 31).

${ }^{7}$ A concepção da cidadania aqui apresentada aproximase daquela desenvolvida por Almeida (2011, p. 33) em sua dissertação de mestrado e por ele denominada de "cidadania da práxis".

${ }^{8}$ Convém esclarecer que Gramsci não descarta o ensino das noções de direitos e deveres. Ao tratar dos conteúdos dos anos iniciais da escola unitária, recomenda que sejam ensinadas as "primeiras noções 'instrumentais' da instrução (ler, escrever, fazer contas, geografia, história)", desenvolvendo-se também, e "sobretudo, a parte relativa aos 'direitos e deveres'", isto é, "as primeiras noções do Estado e da sociedade", as quais, evidentemente, não devem ser abordadas de forma abstrata ou alienada, mas como "elementos primordiais de uma nova concepção do mundo" que venha a se contrapor às concepções tradicionais e "folclóricas" e superá-las (Gramsci, 2006, C 12 $\S 1$, p. 37)
Ao fazer isso, essa escola dá a impressão de que amplia as oportunidades de ascensão, estendendo-as às camadas sociais subalternas. Na prática, porém, considerando que há um tipo de escola profissional para cada grupo social, o que ela faz é "perpetuar as diferenças sociais" e, mais que isso, "cristalizá-las em formas chinesas" (Gramsci, 2006, C 12, § 2, p. 49). ${ }^{6}$

A escola tradicional também perpetuava as diferenças, uma vez que era uma escola oligárquica, voltada "à nova geração dos grupos dirigentes". Mas não era o seu método de ensino que fazia dela uma escola oligárquica, nem sua capacidade para preparar os alunos para os cargos de direção e de controle na sociedade, e sim o fato de não atender igualmente a todos e de existirem escolas diferentes para cada grupo social. Para se reverter essa tendência, é preciso criar "um tipo único de escola", de nível primário e médio, que forme o jovem das camadas populares "como pessoa capaz de pensar, de estudar, de dirigir ou de controlar quem dirige" (Gramsci, 2006, C 12, § 2, p. 49 - grifos meus). Uma escola que cumprisse essa meta estaria, de fato, revelando uma tendência democrática. A proliferação de escolas profissionais, ao contrário, "tende a eternizar as diferenças tradicionais" (Gramsci, 2006, C 12, § 2, p. 49).

O caráter intrinsecamente democrático de uma escola não está, portanto, no fato de qualificar profissionalmente os jovens das camadas populares, mas na sua capacidade de "transformar cada 'cidadão' em 'governante' [assegurando-lhe] o aprendizado gratuito das capacidades e da preparação técnica geral necessárias a essa finalidade" (Gramsci, 2006, C 12, § 2, p. 50 - grifos meus).

Tem-se aqui um elemento essencial para a compreensão da perspectiva gramsciana da cidadania e da sua articulação com a educação. ${ }^{7}$ A cidadania, para ele, não se limita ao conhecimento e à defesa dos direitos e deveres constitucionais, tampouco à aquisição de competências para o ingresso no mercado de trabalho. Tal modelo de cidadania, embora tenha seu valor, no sentido de que pode proporcionar avanços significativos na qualidade de vida das camadas subalternas, é perfeitamente possível de ser praticado sem qualquer questionamento à ordem estabelecida, isto é, à ordem liberal burguesa, à divisão da sociedade em classes, à relação entre dominantes e dominados, dirigentes e dirigidos. Aliás, muito ao contrário, é uma cidadania comprometida com o aperfeiçoamento e a manutenção dessa ordem. Em vez disso, a concepção propugnada por Gramsci aponta, em última instância, para a superação da sociedade de classes, na medida em que supõe, ou mesmo exige, que os subalternos estejam preparados para assumir a posição de governantes, isto é, para deixar sua condição de subalternos, o que só pode ocorrer plenamente com a abolição do modo de produção capitalista, e a escola cumpre um papel decisivo na formação desse cidadão, na medida em que for capaz de formar o jovem das camadas subalternas "como pessoa capaz de pensar, de estudar, de dirigir ou de controlar quem dirige" (Gramsci, 2006, C 12 , $\S 2$, p. 49 - grifos meus) ${ }^{8}$ 
Cabe, porém, perguntar:

$1^{\circ}$ ) Pode a escola, instituição planejada para atender às necessidades do capitalismo, formar cidadãos nessa perspectiva e com esse perfil pensado por Gramsci?

$\left.2^{\circ}\right)$ Caso possa, de que forma ela o faria?

$\left.3^{\circ}\right)$ Que contribuição específica a Filosofia, como componente curricular do ensino médio, poderia oferecer para esta formação cidadã?

Da perspectiva do materialismo mecanicista, a resposta à primeira pergunta seria negativa. Afinal, se a escola, como elemento da superestrutura, é determinada mecanicamente pela estrutura social, não lhe resta alternativa senão a de reproduzir essa estrutura. Admitir, portanto, que essa escola pudesse transformar subalternos em cidadãos com capacidade para se tornarem governantes seria idealismo, alienação, ingenuidade.

A visão de Gramsci, porém, é bastante diversa. Evidentemente, como pensador e militante marxista, não ignora que, sendo elemento da superestrutura, a escola é, em grande medida, determinada pela estrutura social e, por conseguinte, direcionada prioritariamente para a reprodução da sociedade que a engendra. Com efeito, não foram poucas as vezes em que Gramsci denunciou e combateu o caráter classista e "oligárquico" da escola, desde seus textos de juventude, como bem o demonstrou Manacorda (2008, p. 23-59). Veja-se, a título de ilustração, o que ele diz em um desses textos:

A cultura é um privilégio. A escola é um privilégio. E não queremos que seja assim. Todos os jovens deveriam ser iguais diante da cultura. O Estado não deve pagar com o dinheiro de todos a escola para os medíocres e deficientes, mas filhos dos abastados, enquanto exclui dela os inteligentes e capazes, porque filhos de proletários. (Scritti Giovanili, p. 59, apud Manacorda, 2008, p. 33).

Contudo, do ponto de vista da filosofia da práxis, que é uma filosofia materialista mas também dialética, essa determinação não é absoluta, mecânica, unilateral, mas contraditória e recíproca. Gramsci, aliás, não se cansou de combater a leitura mecanicista e dualista do marxismo, particularmente da teoria da estrutura e da superestrutura, combate que se faz presente em diversas passagens de sua obra.

No parágrafo 41 do Caderno 10, para citar apenas um exemplo, Gramsci refuta a posição de Benedetto Croce segundo a qual a filosofia da práxis "'destaca' a estrutura da superestrutura", incorrendo numa espécie de "dualismo teológico" que acaba por afirmar "um 'deus oculto-estrutura'". Para Gramsci, essa interpretação de Croce "não é exata" nem "muito profunda", mas, ao contrário, "vazia e superficial", pois "não é verdade que a filosofia da práxis 'destaque' a estrutura das superestruturas; ao contrário, ela concebe o desenvolvimento das mesmas como intimamente relacionado e necessariamente inter-relativo 
${ }^{9}$ Sociedade civil e sociedade política são, para Gramsci, "dois grandes 'planos' superestruturais". O primeiro se refere ao "conjunto de organismos designados vulgarmente como 'privados'" e cumpre a "função de 'hegemonia' que o grupo dominante exerce em toda a sociedade". O segundo identifica-se com o Estado propriamente dito e exerce o papel de "'domínio direto' ou de comando, que se expressa no Estado e no governo 'jurídico" (Gramsci, 2006, C 12, § 1, p. 20-21).

${ }^{10}$ Sucintamente, guerra de movimento é aquela que visa efetivamente à tomada do poder de Estado, tal como ocorreu, por exemplo, na Revolução Russa de 1917. No Oriente isso foi possível, segundo Gramsci, porque lá a sociedade civil era "primitiva e gelatinosa". No Ocidente, porém, a sociedade civil é muito mais desenvolvida e bem articulada com o Estado, atuando como uma "robusta cadeia de fortalezas e casamatas" em sua defesa. Em sociedades desse tipo só é possível, num primeiro momento, a "guerra de posição", que consiste em lutar no campo da sociedade civil visando a construir uma nova hegemonia (Gramsci, 2002, C 7 . $\S 16$, p. 262). e recíproco" (Gramsci, 2001a, C 10, § 41 [I], p. 369). Além disso, na filosofia da práxis, nem mesmo como metáfora a estrutura poderia ser comparada a um "deus", isto é, a algo imóvel e absoluto, uma vez que ela é concebida como "a própria realidade em movimento" (Gramsci, 2001a, C 10, § 41 [I], p. 369-370).

Embora Gramsci não o afirme explicitamente, o fato de a relação entre estrutura e superestrutura não ser mecânica, mas dialética e de ação recíproca, permite ver a escola como espaço de contradição, campo de batalha pela hegemonia, terreno de "luta cultural para transformar a 'mentalidade' popular" (Gramsci, 2001a, C 10, § 44, p. 398), e esse terreno não pode ser negligenciado pelos intelectuais comprometidos com as camadas sociais subalternas, incluindo, naturalmente, os professores. Em outros termos, é preciso reconhecer que, sendo elemento da sociedade civil, ${ }^{9}$ mesmo a escola atual, que não é ainda a "escola unitária" propugnada por Gramsci, também se constitui em campo de batalha da "guerra de posição", ${ }^{10}$ devendo-se, por conseguinte, identificar as características peculiares da luta a ser travada pelos intelectuaisprofessores no âmbito escolar.

Isso é particularmente relevante no caso do Brasil, onde, para a esmagadora maioria da população - isto é, para os "simples", as pessoas do povo, os subalternos, os pobres -, a escola pública ainda é o principal, se não o único meio de acesso ao saber elaborado (científico, filosófico e artístico) necessário à sua elevação cultural e à formação daquele cidadão concebido por Gramsci.

Portanto, na perspectiva gramsciana, a resposta à primeira pergunta é afirmativa: de fato, a escola, mesmo sendo planejada para atender às necessidades do capitalismo, pode também, contraditoriamente, dentro de certos limites, atuar como instrumento (função de mediação) para a formação de um novo tipo de cidadão, capaz de empreender a crítica a esse modo de produção e de agir conscientemente em favor de sua transformação. Para tanto, porém, é preciso que os intelectuaisprofessores comprometidos com esse objetivo encontrem formas de luta no campo especificamente pedagógico e sejam capazes de fazer frente à tendência da escola de oferecer dominantemente uma formação precária e aligeirada aos alunos das camadas populares, muito distante daquela que seria necessária para convertê-los em cidadãos governantes.

Como, então, os intelectuais-professores poderiam empreender essa luta, de modo a contribuir para formar cidadãos capazes de governar? Entramos, assim, no tema da segunda pergunta, a respeito da qual a escola tradicional parece ter algo a ensinar. Afinal, como observa Gramsci em passagem supracitada, formar as classes dirigentes era algo que ela sabia fazer com maestria.

1) Um primeiro ponto a considerar é seu método de ensino, que, de algum modo, cumpria bem essa função. Ora, em que consistia o método tradicional? Basicamente na transmissão de conhecimentos historicamente produzidos pela humanidade e cuja apropriação era importante para o 
desenvolvimento da capacidade de pensar e de orientar-se na vida com autonomia. Trata-se de conhecimentos como leitura, escrita, cálculo, geografia, história, direitos e deveres, enfim, o saber científico organizado nas diversas disciplinas escolares. Isso significa que o domínio dos conteúdos curriculares era visto pela escola tradicional como essencial para a formação dos futuros dirigentes.

Ora, esse parece ser um aspecto a se recuperar da escola tradicional: a essencialidade dos conteúdos. Se eles são necessários à "aquisição de capacidades de direção" e à formação de "homens superiores" e se o objetivo é estender a todos essas capacidades, transformando-as em progresso de massa, então a escola pública, que é aquela onde estudam as massas, não pode prescindir desses conteúdos, ao contrário, deve empenhar-se em sua socialização. Do contrário, esses saberes, e a cidadania que eles proporcionam aos que os dominam, continuarão sendo privilégio de uma pequena minoria, enquanto os demais permanecerão como "cidadãos" de segunda classe, alijados dos instrumentos culturais que lhes permitiriam se posicionar e intervir na realidade de maneira crítica, consciente, autônoma e efetiva.

Cabe aqui um esclarecimento que é também um alerta: muitos, ao ouvirem falar em transmissão de conteúdos, logo "torcem o nariz" e remetem o pensamento à imagem de uma escola superada, retrógrada, enfadonha, por vezes autoritária, rígida, opressora, disciplinadora, centrada no professor e na memorização mecânica das matérias, na qual os alunos não tinham vez nem voz. É possível que tudo isso realmente tenha feito parte, em maior ou menor escala, do modelo tradicional de ensino. Mas se é verdade que todos esses adjetivos (e talvez mais outros tantos) servem para qualificar certa escola de um determinado tempo e lugar, também é verdade que entre eles e a prática da transmissão de conhecimentos não existe uma relação de necessidade. Pode-se perfeitamente transmitir conteúdos, conhecimentos elaborados, científicos, eruditos, de todas as áreas do saber, sem se adotar uma conduta pedagógica autoritária, castradora, "bancária" (Freire, 1981, p. 65-66). Aliás, as melhores escolas privadas, destinadas aos filhos das elites, parecem fazer isso muito bem, visto que não se cansam de inovar seus métodos de ensino sem jamais abrir mão dos conteúdos; portanto, a crítica aos aspectos negativos da pedagogia tradicional não tem que "jogar fora a criança junto com a água da bacia". Por outro lado, abdicar da transmissão (ou socialização) do conhecimento, por vezes em nome de pedagogias supostamente progressistas e democráticas, ou, ainda, com o argumento falacioso de que aos trabalhadores interessa mais diretamente o ensino profissionalizante para que possam ingressar mais rapidamente no mercado de trabalho e ascender socialmente, é privar os subalternos de se tornarem cidadãos-governantes. Tal postura, que nada tem de democrática, favorece a continuidade da divisão da escola (uma para as elites e outra para os trabalhadores) e a reprodução da desigualdade de classes. No Caderno 11 encontra-se uma nota bastante interessante e até provocativa a respeito da importância da socialização do saber: 
Criar uma nova cultura não significa apenas fazer individualmente descobertas "originais"; significa também, e, sobretudo, difundir criticamente verdades já descobertas, "socializá-las" por assim dizer; e, portanto, transformá-las em base de ações vitais, em elemento de coordenação e de ordem intelectual e moral. O fato de que uma multidão de homens seja conduzida a pensar coerentemente e de maneira unitária a realidade presente é um fato "filosófico" bem mais importante e "original" do que a descoberta, por parte de um "gênio" filosófico, de uma nova verdade que permaneça como patrimônio de pequenos grupos intelectuais. (Gramsci, 2001b, C 11, § 12, Nota IV, p. 95-96 - grifos meus).

Ora, se a capacidade de pensar coerentemente e de maneira unitária a realidade atual é condição para o exercício da cidadania no sentido aqui apresentado, então a transmissão/socialização de conteúdos é essencial para que a escola contribua para esse objetivo.

2) A escola tradicional também era uma escola "desinteressada", no sentido de que as noções que ensinava não visavam a uma "imediata finalidade prático-profissional", mas ao "desenvolvimento interior da personalidade"e à "formação do caráter através da absorção e da assimilação de todo o passado cultural da civilização europeia moderna" (Gramsci, 2006, C 12, § 2, p. 46). O estudo do latim ilustra bem esse fato:

Não se aprendia o latim e o grego para falá-los, para trabalhar como garçom, intérprete ou correspondente comercial. Aprendia-se para conhecer diretamente a civilização dos dois povos, pressuposto necessário da civilização moderna, isto é, para ser e conhecer conscientemente a si mesmo. (Gramsci, 2006, C 12, § 2, p. 46).

Além disso, o estudo do latim atendia a determinadas "exigências pedagógicas e psicológicas", como habituar as crianças a um determinado método de estudo, a "raciocinar, a abstrair esquematicamente [...], a ver em cada fato ou dado o que há nele de geral e de particular, o conceito e o indivíduo" (Gramsci, 2006, C 12, § 2, p. 47). Em suma:

Esse estudo educava sem que tivesse a vontade expressamente declarada de fazê-lo, com uma mínima intervenção "educativa" do professor: educava porque instruía. Experiências lógicas, artísticas, psicológicas eram feitas sem que "se refletisse sobre", sem olhar-se continuamente no espelho, e era feita principalmente uma grande experiência "sintética", filosófica, de desenvolvimento histórico-real. (Gramsci, 2006, C 12, § 2, p. 48).

Essa escola "desinteressada", porém, adverte Gramsci, está em "processo de progressiva degenerescência". Predominam sobre ela "as escolas de tipo profissional, isto é, preocupadas em satisfazer interesses práticos imediatos". Como já foi mencionado, embora esse tipo de escola apareça e seja "louvado como democrático", paradoxalmente, na realidade, "não só é destinado a perpetuar as diferenças sociais, como ainda a cristalizá-las em formas chinesas" (Gramsci, 2006, C 12, § 2, p. 49).

Portanto, para formar o cidadão, tal como aqui ele é caracterizado, a escola não tem que se pautar por princípios utilitaristas e imediatistas 
(como a preparação imediata para o trabalho), antes deve assegurar a todos um período de estudo "desinteressado", de caráter "formativo ainda que 'instrutivo', isto é, rico de noções concretas" (Gramsci, 2006, C 12, $\S 2$, p. 49) que favoreçam o desenvolvimento nos alunos da capacidade de pensar, estudar e dirigir.

3) Uma das críticas que se fazia à escola tradicional era quanto ao caráter repetitivo, mecânico e árido de seu ensino. Tal crítica tinha, de fato, pertinência e legitimidade, mas Gramsci considera que há nelas também "muita injustiça e impropriedade". Afinal,

lida-se com adolescentes, aos quais é preciso fazer com que adquiram certos hábitos de diligência, de exatidão, de compostura até mesmo física, de concentração psíquica em determinados assuntos, que só se podem adquirir mediante uma repetição mecânica de atos disciplinados e metódicos. (Gramsci, 2006, C 12, § 2, p. 46).

Para sustentar sua posição, Gramsci dá um exemplo prático, perguntando:

Um estudioso de quarenta anos seria capaz de passar dezesseis horas seguidas numa mesa de trabalho se, desde menino, não tivesse assimilado, por meio da coação mecânica, os hábitos psicofísicos apropriados? (Gramsci, 2006, C 12, § 2, p. 46).

Evidentemente, não é necessário "retornar aos métodos pedagógicos dos jesuítas" (Gramsci, 2006, C 12, § 2, p. 46), mas certo grau de repetição mecânica, de coação, de imposição parece necessário, pelo menos numa determinada etapa da formação intelectual e física, até que o estudante adquira maturidade e disciplina para realizar por si mesmo as atividades necessárias.

4) A escola tradicional também não descuidava da disciplina. Certas atividades que são para a criança como quebra-cabeças certamente a cansam, e não se deve cansá-la mais que o necessário, diz Gramsci, mas "é sempre necessário [no sentido de que é inevitável] que ela se canse" em alguma medida, "a fim de aprender a se autoimpor privações e limitações de movimento físico, isto é, a se submeter a um tirocínio psicofísico" (Gramsci, 2006, C 12, § 2, p. 51). Na realidade, o estudo é também um trabalho que exige esforço e até certo sofrimento:

Deve-se convencer muita gente de que o estudo é também um trabalho, e muito cansativo, com um tirocínio particular próprio, não só intelectual, mas também muscular-nervoso: é um processo de adaptação, é um hábito adquirido com esforço, aborrecimento e até mesmo sofrimento. (Gramsci, 2006, C 12, § 2, p. 51).

Há os que pensam que o ingresso das massas populares na escola requer o afrouxamento da disciplina. Afinal, a criança oriunda dessas camadas enfrenta mais dificuldades que a criança de uma família de 
intelectuais, que "supera mais facilmente o processo de adaptação psicofísico" (Gramsci, 2006, C 12, § 2, p. 52). Essa diferença quanto às dificuldades escolares, aliás, faz com que muitas pessoas do povo acreditem que existe uma espécie de "truque" que a escola usa contra elas ou, então, que são naturalmente menos inteligentes que os demais que desenvolvem com facilidade e rapidez "o trabalho que custa aos seus filhos lágrimas e sangue"; no entanto, é preciso "resistir à tendência a facilitar o que não pode sê-lo sob pena de ser desnaturado" (Gramsci, 2006, C 12, § 2, p. 52). Por que o ensino não pode ser facilitado? Porque, como foi dito acima, ele é também, por natureza, um trabalho - por vezes inevitavelmente cansativo, sofrido. Ora, um ensino inteiramente desprovido dessas características seria desnaturado, isto é, perderia a sua natureza, a sua essência, a sua identidade, enfim, deixaria de ser o que é: ensino. Nesse sentido, o afrouxamento da disciplina para as crianças e jovens das classes subalternas significaria, na prática, impedir o seu acesso efetivo à educação e, por conseguinte, à cidadania. É preciso, portanto, encontrar outras formas de compensar e superar as dificuldades sentidas por essas crianças e jovens (dificuldades que, de fato, são maiores que as dos demais estudantes), sem, no entanto, permitir que isso represente oferecer a elas um ensino de qualidade inferior, ou subestimar sua inteligência e sua capacidade de aprender e de avançar nos estudos. Na prática, essa subestimação significaria privá-las de uma educação com a mesma qualidade daquela oferecida aos filhos das elites.

5) Afirmar a necessidade de certa coação, mecanicidade e disciplina não implica defender uma relação autoritária entre professor e aluno. A esse respeito, vale lembrar a figura do "filósofo democrático" (grifo meu), esboçada por Gramsci no parágrafo 44 do Caderno 10, e que pode inspirar a relação professor-aluno em sala de aula. Aqui a contribuição vem da pedagogia moderna e não da tradicional.

Para Gramsci (2001a, C 10, § 44, p. 398 - grifos meus), o trabalho do filósofo deve ser concebido

[...] não mais apenas como elaboração "individual" de conceitos sistematicamente coerentes, mas além disso, e sobretudo, como luta cultural para transformar a "mentalidade" popular e difundir as inovações filosóficas que se revelem "historicamente verdadeiras" na medida em que se tornem concretamente, isto é, histórica e socialmente, universais.

Observe-se que, novamente, transparece a ideia da transmissão de saberes elaborados.

Transformar a mentalidade popular significa também transformar o ambiente cultural em que o filósofo vive e atua. Mas o próprio filósofo individual, ou melhor, a sua "personalidade histórica", também é afetada pela "relação ativa" que existe entre ele e o ambiente cultural que pretende modificar e que para ele "funciona como professor", "obrigando-o a uma permanente autocrítica" em relação às suas posições e estratégias de ação (Gramsci, 2006, C 12, § 2, p. 399-400). Em outras palavras, ao mesmo 
tempo que educa o ambiente, o filósofo é também por ele educado. Há, portanto, uma relação dialética entre ambos, semelhante àquela que se estabelece entre professor e aluno: uma "relação ativa, de vinculações recíprocas", de modo que "todo professor é sempre aluno e todo aluno, professor" (Gramsci, 2001a, C 10, § 44, p. 399).

Este seria um novo tipo de filósofo denominado por Gramsci de "filósofo democrático": aquele que é "consciente de que a sua personalidade não se limita à sua individualidade física, mas é uma relação social ativa de modificação do ambiente cultural" (Gramsci, 2001a, C $10, \S 44$, p. 400). É por isso que, como diz Giorgio Baratta (2010, p. 36), esse filósofo é capaz de pensar junto com aqueles cuja mentalidade quer modificar. Essa possibilidade não decorre apenas de sua vontade individual ou de seu compromisso político, mas também de sua condição ontológica, de um ser que se constitui como "relação social ativa". O requisito para a existência desse novo tipo de filósofo é a "liberdade de pensamento e de expressão do pensamento" (Gramsci, 2001a, C 10, § 44, p. 400).

Essa imagem do filósofo democrático vale também para o professor comprometido com a "luta cultural para transformar a 'mentalidade' popular". Com efeito, também ele mantém uma relação ativa e de vinculações recíprocas com o ambiente cultural que quer modificar (a escola, os alunos, os pais), o qual reage sobre ele, obrigando-o a uma permanente autocrítica. Aqui se aplica ainda mais explicitamente o princípio de que "todo professor é sempre aluno e todo aluno, professor". Não há, portanto, lugar para o autoritarismo, o dogmatismo, o sectarismo, a arrogância, enfim, para a prática "bancária" da educação, na qual o professor, que sabe, ensina e comanda, é o protagonista, e o aluno, que não sabe, aprende e obedece, é coadjuvante. Se o que se pretende é que a escola capacite os subalternos a se tornarem cidadãos-governantes, isto é, que ajude a "fazer coincidir governantes e governados" (Gramsci, 2006, C 12, § 2, p. 50), então o processo pedagógico tem que se pautar, desde o início até o final, por esse mesmo princípio. Novamente as palavras de Giorgio Baratta (2010, p. 38) ajudam a esclarecer essa concepção gramsciana da relação professor-aluno, intelectual-povo:

\begin{abstract}
A escola que Gramsci tem em mente - cujo princípio moderno é o de que "todo professor é sempre aluno e todo aluno, professor" - realiza in vitro o modelo de uma sociedade capaz de promover um processo de superação da oposição "entre camadas intelectuais e não intelectuais, entre governantes e governados, entre elites e seguidores, entre dirigentes e dirigidos".
\end{abstract}

Daí a importância de que se instaure em sala de aula uma atmosfera de liberdade de pensamento e de expressão das opiniões e dos questionamentos, de respeito mútuo, de disposição para ouvir e colaborar uns com os outros, a fim de se favorecer gradativamente o amadurecimento e a autonomia dos estudantes.

Esses são alguns aspectos que, a meu ver, de uma perspectiva gramsciana, poderiam nortear uma prática educativa voltada para o preparo dos jovens para outra cidadania, diferente daquela proposta pela 
${ }^{11}$ Todos os homens são filósofos no sentido de que todos são capazes de pensar. Como diz Gramsci, "é impossível pensar em um homem que não seja também filósofo, que não pense, precisamente porque o pensar é próprio do homem como tal" (Gramsci, 2001a, C 10, § 52, p. 411). Esse tema será retomado e complementado no Caderno 11 (Gramsci, 2001b, C 11, § 12, p. 93).

${ }^{12}$ As considerações a seguir, a respeito da história da filosofia foram mais desenvolvidas em Silveira (2012). legislação educacional. Resta, agora, analisar o papel da Filosofia como disciplina nesse preparo. Entramos, finalmente, na terceira pergunta.

Se o cidadão desejado por Gramsci é aquele que adquiriu capacidade de pensar autonomamente a fim de se tornar dirigente, então certamente a Filosofia, pela sua própria natureza reflexiva, tem algo com que contribuir para essa cidadania. Mas como ela ensina a pensar?

No Caderno 10, após demonstrar que, num certo sentido, "todos os homens são 'filósofos'", 11 Gramsci esclarece que há também uma diferença importante entre o filósofo profissional ou especialista e os demais. Essa diferença consiste no fato de que o filósofo especialista pensa "com maior rigor lógico, com maior coerência, com maior espírito de sistema do que os outros homens" e, além disso, conhece e sabe explicar toda a história do pensamento (Gramsci, 2001a, C 10, § 52, p. 410). Ora, por que o filósofo profissional pensa com mais rigor lógico, coerência e sistematicidade que os demais? Porque estudou sistematicamente o pensamento dos filósofos que o antecederam na história, isto é, aqueles pensadores que constituíram a chamada história da filosofia e que desenvolveram métodos rigorosos de pensar sobre os problemas que consideraram relevantes em seu tempo e que lhes possibilitaram formular suas filosofias. Portanto, o estudo das obras dos filósofos é um meio eficaz para o aprendizado tanto do seu pensar rigoroso quanto do conteúdo mesmo desse pensar (as suas filosofias propriamente ditas), devendo por isso fazer parte de um ensino de Filosofia comprometido com o preparo do cidadão-governante. ${ }^{12} \mathrm{Na}$ relação pedagógica, o professor de Filosofia está para o estudante assim como o filósofo profissional está para os demais. O desafio que se apresenta ao professor é justamente o de criar as mediações didáticas que permitam aos alunos avançar de um filosofar espontâneo, de senso comum, para um filosofar qualitativamente superior, mais rigoroso, crítico, coerente e mais próximo do filosofar do filósofo especialista. Para tanto, é imprescindível o contato dos estudantes com as obras dos filósofos, com a história da filosofia. A esse respeito, Lidia Rodrigo (2009, p. 71) afirma:

Na conjuntura posta pelo atual ensino médio, cabe ao professor ser
o mediador entre a filosofia e os alunos iniciantes, que não possuem
ainda as qualificações requeridas para ter acesso a esse saber por conta
própria, o que supõe que ele seja capaz de traduzir em termos simples
um saber especializado. Para dar conta dessa tarefa, muitos desafios
precisam ser superados, desde as deficiências de sua própria formação
e as carências de seus alunos, até condições institucionais adversas
ao ensino da disciplina, como, por exemplo, o tempo exíguo que lhe é
destinado na grade curricular.

Mas o estudo da história da filosofia cumpre ainda outro papel também fundamental para a formação do cidadão no sentido aqui discutido. Como diz Gramsci, todos somos "filósofos", ainda que cada um a seu modo e inconscientemente, pois todos possuímos uma concepção do mundo que orienta nossas ações cotidianas. Adquirimos essa concepção do mundo, essa "filosofia", espontaneamente (daí Gramsci denominá-la de "filosofia espontânea"), de modo acrítico, inconsciente, pelo simples fato de 
vivermos em sociedade. Por isso, pode-se dizer que ela nos é "imposta" pelo ambiente e pelos grupos sociais dos quais participamos: a família, a escola, a igreja, a vizinhança, os clubes, os amigos, o trabalho, entre outros. Em vista disso, Gramsci (2001b, C11, § 12, p. 93-94) lança o seguinte questionamento:

[...] é preferível "pensar" sem disto ter consciência crítica, de uma maneira desagregada e ocasional, isto é, "participar" de uma concepção do mundo "imposta" mecanicamente pelo ambiente exterior, por um dos muitos grupos sociais nos quais todos estão automaticamente envolvidos desde sua entrada no mundo consciente [...], ou é preferível elaborar a própria concepção do mundo de uma maneira consciente e crítica e, portanto, em ligação com este trabalho do próprio cérebro, escolher a própria esfera de atividade, participar ativamente na produção da história do mundo, ser o guia de si mesmo e não mais aceitar do exterior, passiva e servilmente, a marca da própria personalidade?

Evidentemente, a segunda opção é a única coerente com a noção de cidadania aqui apresentada. Mas como "elaborar criticamente a própria concepção do mundo"? Inicialmente é preciso reconhecer que somos "produto do processo histórico até hoje desenvolvido", o qual deixou em cada um de nós "uma infinidade de traços acolhidos sem análise crítica" (Gramsci, 2001b, C 11, p. 94, nota I). Ora, grande parte desses traços nos foi legada pela filosofia elaborada ao longo da história e que permanece viva até os dias de hoje, incluindo a filosofia dos "filósofos profissionais", que "deixou estratificações consolidadas na filosofia popular". Por isso, elaborar criticamente a própria concepção do mundo requer, também, conhecer e criticar essa "filosofia até hoje existente", a fim de identificar, explicitar, compreender, problematizar e superar essas estratificações que dela assimilamos acriticamente.

Esta é mais uma razão pela qual é importante o estudo da história da filosofia; sem ele não seria possível conhecer os fundamentos filosóficos de nossa própria concepção do mundo e, muito menos, reelaborá-la criticamente para que deixe de ser "um conjunto desagregado de ideias e de opiniões" (Gramsci, 2001b, C 11, p. 98) adquiridas inconscientemente e se torne "unitária e coerente" (Gramsci, 2001b, C 11, p. 94, nota I). Nesse sentido, tal estudo significa também uma forma de "conhecer-te a ti mesmo", necessário para que o estudante avance na conquista da autonomia para orientar-se na vida e ter iniciativa, condição essencial ao exercício da cidadania.

Ainda a respeito da história da filosofia, Gramsci afirma no Caderno 12: "A filosofia descritiva tradicional, reforçada por um curso de história da filosofia e pela leitura de um certo número de filósofos, parece ser praticamente a melhor coisa." (Gramsci, 2006, C 12, § 2, p. 51). Mesmo que essa "filosofia descritiva e definidora" tenha, muitas vezes, inevitavelmente um caráter abstrato (como ocorre também com a gramática, a matemática e a lógica formal), ela é uma "necessidade pedagógica e didática" (Gramsci, 2006, C 12, § 2, p. 51). Tanto as regras da lógica e da gramática quanto os conceitos matemáticos e filosóficos não são inatos; antes, precisam 
ser adquiridos "mediante o trabalho e a reflexão" (Gramsci, 2006, C 12, $\S 2$, p. 51). Como foi dito acima, é preciso deixar claro aos alunos que o estudo é também um trabalho árduo, cansativo: "é um hábito adquirido com esforço, aborrecimento e até mesmo sofrimento" (Gramsci, 2006, C 12 , § 2, p. 51). Mas, mesmo quando o ensino é esquemático e abstrato, a aprendizagem ocorre de um "modo 'vivo'",

[...] já que o discente não é um disco de vitrola, não é um recipiente passivamente mecânico, ainda que a convencionalidade litúrgica dos exames assim o faça parecer por vezes. A relação de tais esquemas educativos com o espírito infantil é sempre ativa e criadora, como ativa e criadora é a relação entre o operário e seus utensílios de trabalho. (Gramsci, 2006, C 12, § 2, p. 51).

Isso não quer dizer que a história da filosofia deva ser trabalhada de forma abstrata e esquemática. Na perspectiva de Gramsci, o objetivo do ensino da Filosofia não deve ser "informar historicamente o aluno sobre o desenvolvimento da filosofia passada", mas, antes, "formá-lo culturalmente", a fim de "ajudá-lo a elaborar criticamente o próprio pensamento". Para tanto, deve-se "partir do que o aluno já conhece, da sua experiência filosófica", demonstrando que ele possui essa experiência, "que é um 'filósofo' sem o saber" (Gramsci, 2001b, C 11, p. 119). Ora, considerando que, em média, os alunos não têm "mais do que informações soltas e fragmentárias, carecendo de qualquer preparação metodológica e crítica", o ponto de partida acaba sendo o próprio senso comum e até mesmo a religião; somente após essa etapa é que se parte para a abordagem dos "sistemas filosóficos" (Gramsci, 2001b, C 11, p. 119). Isso exige que o professor conheça, ao menos parcialmente, o universo cultural dos alunos e seja capaz de articular a esse universo os problemas que serão objeto da reflexão em sala de aula.

Na realidade, a história da filosofia como conteúdo do ensino da Filosofia não deve ser vista como um fim em si mesmo, mas como um referencial necessário para a reflexão sobre os problemas extraídos da realidade vivida pelos alunos, do senso comum, auxiliando-os a compreendê-los de modo mais rigoroso e crítico e instrumentando-os para intervir mais eficazmente visando à sua superação. Desse modo, a história da filosofia deixa de ser vista como um conteúdo abstrato, distante da vida dos alunos, adquirindo para eles um significado concreto e prático.

\section{Conclusão}

Pelo exposto, observa-se que tanto na Constituição quanto na legislação educacional examinada está presente uma concepção liberal da cidadania, que a entende como exercício consciente de direitos e deveres e como preparo para atender satisfatoriamente às exigências do mercado de trabalho. É em relação a esta cidadania que a Filosofia é considerada necessária, a ponto de justificar sua presença no currículo do ensino 
médio como disciplina obrigatória. Pelo menos é essa a expectativa oficial em relação a ela.

Isso permite compreender, ao menos em parte, os motivos pelos quais a Filosofia pôde retornar ao ensino médio como disciplina obrigatória, após seu afastamento compulsório no período pós-1964. ${ }^{13}$ No "Novo Ensino Médio", pensado para atender às exigências da atual fase de desenvolvimento do capitalismo, a Filosofia e as demais disciplinas humanísticas cumprem um papel importante na configuração de um novo perfil de trabalhador, dotado de certas "competências" cognitivas e intelectuais que somente essas ciências lhe podem oferecer. Mas, paradoxalmente, essas mesmas condições objetivas que permitem (e até exigem) o retorno da Filosofia submetendo-a às exigências do capital também fornecem as bases materiais que tornam possível e efetiva a luta pela consolidação do espaço dessa disciplina no currículo. Uma vez consolidado esse espaço, e tendo em vista o caráter contraditório da escola, abrem-se novas perspectivas para a constituição e um ensino de Filosofia comprometido com uma outra concepção da cidadania.

Evidentemente, tendo em vista que vivemos (ainda) em uma sociedade capitalista na qual o liberalismo é a visão de mundo hegemônica, a compreensão por todos os cidadãos de seus direitos e deveres e sua qualificação para o trabalho são, de fato, algo necessário e pelo qual a educação deve se responsabilizar - ainda mais no Brasil, onde sequer os direitos previstos na Constituição (incluindo o direito à educação) são assegurados a todos plenamente. Isso, porém, não significa que devam ser acatados sem reflexão, sem questionamento, acriticamente. Afinal, os direitos e deveres instituídos em uma determinada sociedade, assim como os princípios e valores nos quais eles se baseiam, não são eternos e imutáveis, tampouco neutros e imparciais; são, ao contrário, historicamente produzidos em resposta às necessidades econômicas, políticas e culturais postas em cada época. Alteradas as circunstâncias que produziram essas necessidades, alteram-se também os direitos e deveres. De fato, há situações que, no passado, eram tidas como de direito (a escravidão, por exemplo) e que hoje já não se sustentam como tal, e vice-versa: direitos que no passado eram inconcebíveis e que, atualmente, são amplamente reconhecidos (por exemplo, a liberação feminina e a união civil entre pessoas homoafetivas). Além disso, é interessante notar que direitos conquistados também podem deixar de ser reconhecidos, dependendo da correlação de forças políticas de cada contexto. Veja-se, por exemplo, o caso de certos direitos trabalhistas que atualmente estão ameaçados em nome da desoneração das empresas, do aumento de sua competitividade e da redução do chamado "custo Brasil".

Tudo isso mostra a importância de que os direitos e deveres, os valores nos quais eles se fundamentam e a noção de cidadania derivada desses valores sejam constantemente submetidos à reflexão, à problematização, à análise crítica. Essa é uma tarefa que compete à escola e, de um modo particular, à Filosofia, pela sua natureza histórica, reflexiva e crítica. Mas, para que isso ocorra, é preciso que os educadores, em especial os $\overline{{ }^{13} \text { A esse respeito, ver Silveira }}$ (1994, 2009). 
professores-filósofos, reconheçam a sala de aula como campo de batalha da "guerra de posições" e não abdiquem de travar ali, cotidianamente, a luta cultural pela transformação da "mentalidade" popular, tendo em vista a construção de uma nova hegemonia que conduza à superação da sociedade de classes. É no seio dessa luta que se constrói, passo a passo, uma nova cidadania que signifique de fato proporcionar a cada cidadão as condições para que venha a se tornar governante.

\section{Referências bibliográficas}

ALMEIDA, Edson de Souza. Ensino de filosofia no nível médio: por uma cidadania da praxis. 2011. Dissertação (Mestrado em Educação) Universidade Estadual de Campinas (Unicamp), 2011.

BARATTA, Giorgio. Escola, filosofia e cidadania no pensamento de Gramsci: exercícios de leitura. Pro-Posições, Campinas, v. 21, n. 1, abr. 2010. Disponível em: < http://www.scielo.br/scielo.php?script=sci arttext\&pid $=$ S0103-73072010000100003\&lng = pt\&nrm $=$ iso\&tlng $=$ pt>. Acesso em: 12 set. 2011.

BRASIL. Lei n ${ }^{\circ}$ 9.394, de 20 de dezembro de 1996. Estabelece as diretrizes e bases da educação nacional. Disponível em: < http://www. planalto.gov.br/ccivil_03/Leis/L9394.htm>. Acesso em: 5 set. 2011.

BRASIL. Lei $n^{\circ} 11.684$, de 2 de junho de 2008. Altera o art. 36 da Lei no 9.394, de 20 de dezembro de 1996, que estabelece as diretrizes e bases da educação nacional, para incluir a Filosofia e a Sociologia como disciplinas obrigatórias nos currículos do ensino médio. Disponível em: <http://www.planalto.gov.br/ccivil_03/_Ato2007-2010/2008/Lei/ L11684.htm>. Acesso em: 6 set. 2011.

BRASIL. Ministério da Educação (MEC). Secretaria de Educação Básica (SEB). Conhecimentos de Filosofia. In: . Orientações curriculares para o ensino médio: Ciências Humanas e suas tecnologias. Brasília, 2006. v. 3, p. 15-42.

BRASIL. Ministério da Educação (MEC). Secretaria de Educação Media e Tecnológica. Parâmetros curriculares nacionais: ensino médio. Brasília, 1999.

DELORS, J. et al. Educação um tesouro a descobrir: relatório para a Unesco da Comissão Internacional sobre Educação para o século XXI. São Paulo: Cortez; Brasília: Unesco, MEC, 1998.

FREIRE, Paulo. Pedagogia do oprimido. Rio de Janeiro: Paz e Terra, 1981. 
GRAMSCI, A. Caderno 10 (1932-1935) - A filosofia de Benedetto Croce. In: . Cadernos do Cárcere. Trad. Carlos Nelson Coutinho.

Rio de Janeiro, Civilização Brasileira, 2001a. v. 1, p. 275-430.

GRAMSCI, A. Caderno 11 (1932-1933) - Introdução ao Estudo da

Filosofia. In: . Cadernos do Cárcere. Trad. Carlos Nelson

Coutinho. Rio de Janeiro, Civilização Brasileira, 2001b. v. 1, p. 81-226.

GRAMSCI, A. Caderno 7. In: . Cadernos do Cárcere. Trad.

Carlos Nelson Coutinho. Rio de Janeiro: Civilização Brasileira, 2002.

GRAMSCI, A. Caderno 12 (1932): Apontamentos e notas dispersas para um grupo de ensaios sobre a história dos intelectuais. In:

Cadernos do Cárcere. Trad. Carlos Nelson Coutinho. Rio de Janeiro:

Civilização Brasileira, 2006. v. 2, p. 13-53.

HOUAISS. Dicionário da Língua Portuguesa. Disponível em: http:// houaiss.uol.com.br/busca.

MANACORDA, Mario Alighiero. O princípio educativo em Gramsci: americanismo e conformismo. Campinas: Alínea, 2008.

RODRIGO, Lídia Maria. Filosofia em sala de aula: teoria e prática para o ensino médio. Campinas: Autores Associados, 2009.

SILVEIRA, R. J. T. A história da filosofia no ensino de Filosofia: considerações a partir de Gramsci. Revista Sul-Americana de Filosofia e Educação (Resafe), Brasília, n. 17, p. 89-105, nov. 2011/ abr. 2012. Disponível em: <http://seer.bce.unb.br/index.php/resafe/issue/ view/714>.

SILVEIRA, R. J. T. Filosofia e segurança nacional: o afastamento da Filosofia do currículo do ensino médio no contexto do regime civilmilitar pós-1964. In: SILVEIRA, Renê J. T.; GOTO, Roberto (Org.). A filosofia e seu ensino: caminhos e sentidos. São Paulo: Loyola, 2009.

SILVEIRA, R. J. T. O afastamento e o retorno da Filosofia ao segundo grau no período pós-64. Pro-Posições, Campinas, v. 5, n. 3, [15], p. 7791, nov. 1994.

SILVEIRA, R. J. T. Teses sobre o ensino de Filosofia no nível médio. In SILVEIRA, Renê J. T.; GOTO, Roberto (Org.). Filosofia no ensino médio: temas, problemas e propostas. São Paulo: Loyola, 2007. p. 77-118. 
Renê José Trentin Silveira, doutor em Educação pela Universidade Estadual de Campinas (Unicamp), é professor do Departamento de Filosofia e História da Educação da Faculdade de Educação dessa universidade e membro do Grupo de Pesquisa Paideia e da Linha de Pesquisa "Ensino de Filosofia".

rene@unicamp.br

Recebido em 9 de novembro de 2011.

Aprovado em 7 de novembro de 2012. 